\title{
Inclusion complex between beta-cyclodextrin and phenylphosphonicdiamide as novel bio-based flame retardant to epoxy: Inclusion behavior, characterization and flammability
}

Xiaomin Zhao, Dan Xiao, Juan Picón Alonso, De-Yi Wang

highligts

- A bio based flame retardant (IC) was synthesized via inclusion behavior

- Impact of IC on thermal stability and flame retardancy of EP was inve stigat ed

- Flame reta rdant mechanism of EP/IC was proposed

\section{graphical abstract}
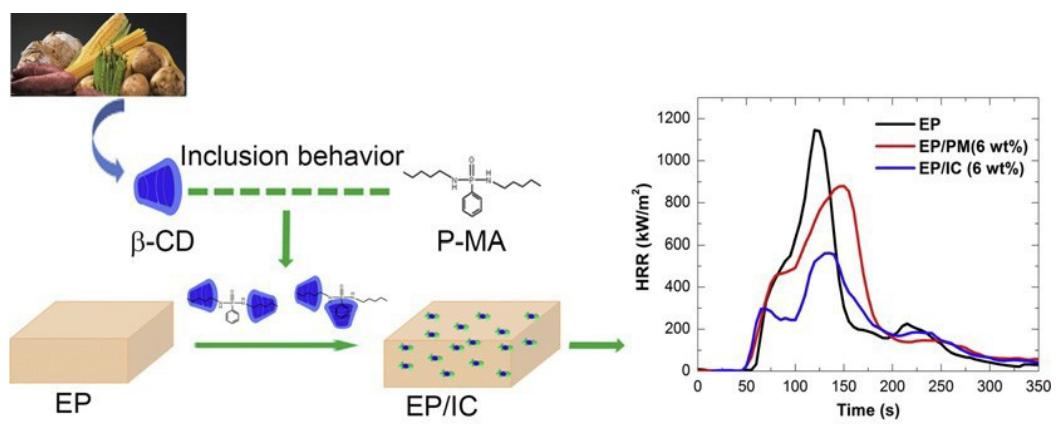

Flame retardancy

abstract

The aim of this work was to study the impact of inclusion complex (IC) between $\beta$ cyclodextrin ( $\beta$ CD) and $N, N^{\prime}$ diamyl p phenylphosphonicdiamide (P MA) on the thermal stability and flame retardancy of epoxy resin (EP) IC was synthesized via inclusion process and characterized by ${ }^{1} \mathrm{H}$ nuclear magnetic resonance (NMR), $\mathrm{X}$ ray dif fraction (XRD), differential scanning calorimeter (DSC) and scanning electron microscopy with $\mathrm{X}$ ray microanal ysis (SEM EDS) ${ }^{1} \mathrm{H}$ NMR was used to identify the mole ratio of $\beta$ CD/P MA in IC, shown that their mole ratio was1 05 The inclusion complex (IC) was proposed to be a char pro moter in EP via a combination of the properties of $b$ CD and P MA during the combustion. By incorporating the IC, the fla me retardancy of EP was expected to be improved Thermal gravimetric analysis (TGA) showed that the thermal stability of IC was better than those of P MA and physical mixture of $\beta$ CD and P MA (PM) The impact of IC and PM on thermal stability and flame retardancy in EP were studied by TGA, limiting oxyge n index (LOI), UL 94 and cone calorimeter tests The heat and smoke releases of EP/IC were suppressed compared with those of EP and EP/PM

\section{Introduction}

Thermoset polymer, epoxy resin is applied in numerous fields such as transportation, aircraft and electronic\&electrical industrials (EE) 
owing to its high performances on mechanical, electrical and chemical resistance [1,2]. However, the intrinsic flammable property of epoxy resin brings fire hazard to these applications [3]. In last 10 years, the de velopment of halogen free eco friendly flame retardant polymer com posite from bio based compounds is becoming a new trend [4]. Many bio based compounds were used to develop novel flame retardant for polymers, such as phytic acid [5], natural polysaccharide [6], cyclodex trin [7 9], deoxyribonucleic acid (DNA) [10] from animal and protein [11].

Cyclodextrins (CDs) are synthetic substances obtained from the en zymatic degradation of polysaccharides (starch) [12]. The structures of CDs are truncated cone shaped with a hollow cone cavity. The hydro phobic cavity of CDs is able to form non covalent host guest inclusion complex that has been widely used in diverse research fields such as pharmacology, food and agriculture [13 16]. The size and dimension of the cavity differed with the number of glucose unit. $\alpha, \beta$ and $\gamma \mathrm{CD}$ are the well known members of CDs, which have 6, 7 and 8 glucose unit, respectively [17]. Among these CDs, $\beta$ CD is the most frequently studied in order to form host guest inclusion complex $[16,18]$. In recent reports, $\beta C D$ and its derivatives were applied in flame retardant ther moplastic polymer materials [4]. For instance, intumescent flame retar dant grouped by ammonium polyphosphate, melamine and $\beta \mathrm{CD}$ increased LOI value of poly (lactic acid) (PLA) from 19.8\% to $34.2 \%$ with 20 wt\% loading [19]. The residue of $\beta$ CD was increased by $>$ $10 \mathrm{wt} \%$ at $400{ }^{\circ} \mathrm{C}$ after the inclusion behavior with triphenyl phosphate (TPP) [20]. J. Alongi et al. reported flame retardants containing cyclo dextrin nanosponges and phosphorus compounds. These flame retar dant showed high yield of char residue under nitrogen $\left(\mathrm{N}_{2}\right)$, whereas the initial thermal decomposition occurred at low temperature (< $200{ }^{\circ} \mathrm{C}$ ) [21]. In the above studies, $\beta \mathrm{CD}$ exhibited high charring ability in polymer materials under acid condition.

In current researches, halogen free flame retardants are widely de veloped to replace some halogenated flame retardants to epoxy resin [22,23]. Many researchers, such as Döring [24 26], Schartel [27 30], Yang [31 33], Hu [34 37] and Toldy [38 40], have reported numerous types of phosphorous nitrogen containing flame retardants to epoxy resin. 9,10 dihydro 9 oxa 10 phosphaphenanthrene 10 oxide (DOPO) and its derivatives are the most reported flame retardants in epoxy resin. Döring et al. [24] reported five novel rod shape DOPO derivatives to D.E.N. $438^{\mathrm{TM}}$ epoxy resin. A good flame retardant epoxy system was shown as phosphorous percentage reached $1 \mathrm{wt} \%$. DOPO based aminic hardeners were reported to epoxy resin by Thompson [41] and Yao [42]. Schartel et al. [30] linked DOPO structure to a star shaped aliphatic molecule to synthesize novel flame retardant named as DOPP and DOPI. LOI of carbon fiber reinforced RTM 6/DOPI was increased evidently from $33.2 \%$ to $47.7 \%$ compared with reference sample. Both Bourbigot [43] and Yang [33] reported a good synergistic effect between polyhedral oligomeric silsesquioxanes (POSS) based structures and phosphorous containing flame retardants in epoxy resins. Wang et al. [44] reported a serial of phenylphosphonate based flame retardants which endowed epoxy resin with V 0 rating in UL 94 test at 5 wt\% flame retardant load ing. $\mathrm{N}, \mathrm{N}^{\prime}$ diamyl p phenylphosphonicdiamide (P MA) was one phenylphosphonate based flame retardant which was reported in our previous report [45]. The flammability of bi functional diglycidyl ester of bisphenol A based epoxy (EP) was reduced after the addition of $\mathrm{P}$ MA. 5 wt\% loading of P MA increased LOI of EP from $22 \%$ to $32 \%$ and re markably decreased peak of heat release rate (pHRR) of EP from 1079 $\mathrm{kW} / \mathrm{m}^{2}$ to $469 \mathrm{~kW} / \mathrm{m}^{2}$. However, the thermal stability of EP/P MA was lowered compared with EP due to the low thermal stability of P MA.

Under the consideration that $\beta \mathrm{CD}$ acted as nature charring precur sor and $\mathrm{P}$ MA acted as acid source, the aim of this work was to study the impact of inclusion complex (IC) between $\beta$ CD and P MA on flame retardancy of EP compared with that of PM in EP. Moreover, the inclu sion behavior was expected to improve thermal stability of P MA. The inclusion behavior was characterized by diverse methods: ${ }^{1} \mathrm{H}$ NMR, XRD, DSC and SEM EDS. TGA was used to study the impact of inclusion behavior on thermal properties of $\beta \mathrm{CD}$ and P MA. Meanwhile, the im pact of PM and IC on thermal properties of EP was also studied. The flammability of EP, EP/PM and EP/IC was investigated by limiting oxy gen index (LOI), UL 94 and cone calorimeter tests. The flame retardant mechanism was proposed to explain the results of flame retardancy in this work.

\section{Experimental}

\subsection{Materials}

Phenylphosphonic dichloride (PPDCl, 90\%), amylamine (MA, 98\%), $\beta C D$, diethyl ether and triethylamine (TEA) were purchased from Sigma Aldrich Corporation and used without any further purification. All the chemical regents used in this work were anhydrous. Deionized water was obtained from IMDEA materials laboratory. Epoxy resin (Brand name, EPC) was purchased from Faserverbundwerkstoffe ${ }^{\circledR}$ composite technology. Epoxy equivalent of EPC was 0.54. The curing agent, 4,4 diaminodiphenylsulfone (DDS) was supplied by Sigma Al drich Corporation.

\subsection{Synthesis of flame retardant $P M A \quad\left(N, \quad N^{\prime}\right.$ diamyl $p$ phenylphosphonicdiamide)}

The synthesis of P MA was synthesized according to our previous work [45] the structure of P MA was showed in Fig. 1c. MA (0.21 mol) and TEA (0.2 mol) were dissolved in $200 \mathrm{ml}$ diethyl ether at $05{ }^{\circ} \mathrm{C}$ in three neck flask. Then into the flask was added dropwise the mixture of PPDCl $(0.1 \mathrm{~mol})$ and diethyl ether $(100 \mathrm{ml})$. The whole mixture reacted at $05{ }^{\circ} \mathrm{C}$ for $2 \mathrm{~h}$ and then the reaction continued at room tem perature (RT) for $5 \mathrm{~h}$. After the reaction finished, the solid liquid mix ture was filtered off to remove triethylamine hydrochloride salt and the filtrate was evaporated under vacuum to obtain the crude product of P MA. The product was purified by washing with deionized water for three times. P MA: yellow liquid at $25{ }^{\circ} \mathrm{C}$; yield, $90 \%$; ${ }^{1} \mathrm{H}$ NMR (DMSO $\left.d_{6}\right): \delta(\mathrm{ppm}), 7.87 .4(\mathrm{Ar} \mathrm{H}, 5 \mathrm{H}) ; 5.8(=\mathrm{CH}, 2 \mathrm{H}) ; 5.14 .9$ $\left(=\mathrm{CH}_{2}, 4 \mathrm{H}\right) ; 3.4\left(-\mathrm{CH}_{2}-, 4 \mathrm{H}\right) ;{ }^{13} \mathrm{C}$ NMR $\left(\right.$ DMSO $\left.d_{6}\right): \delta(\mathrm{ppm}), 137.8$, $135.5,134.3,131.2,130.6,127.8,114.2,42.4 ;{ }^{31}$ P NMR (DMSO $\left.d_{6}\right): \delta$ (ppm), 19.8.

\subsection{Preparation of inclusion complex (IC) of $\beta C D$ and $P M A$}

$\beta C D$ (11.35 g, $0.01 \mathrm{~mol})$ was dissolved into $115 \mathrm{ml}$ deionized water to form $\beta$ CD aqueous solution at $65^{\circ} \mathrm{C}$. Then P MA ( $2.96 \mathrm{~g}, 0.01 \mathrm{~mol}$ ) was added dropwise into the prepared aqueous solution at $65^{\circ} \mathrm{C}$ and stirred for $2 \mathrm{~h}$. After cooling for $24 \mathrm{~h}$ at room temperature, the rough product of IC was obtained after the filtration of the solid liquid mix ture. Finally, IC was obtained after washing the rough product by ace tone for three times. The yield of IC was $85 \%$. In order to compare with IC, the physical mixture (PM) of $\beta C D$ and P MA was prepared. $\beta C D$ and P MA was mixed with molar ratio: 1:0.5 though solving the two chemicals in dimethylsulfoxide (DMSO) at room temperature. Then DMSO was evaporated by rotating evaporating machine to get PM.

\subsection{Preparation of epoxy composites of EP, EP/PM and EP/IC}

Reference epoxy (EP) was prepared as below: curing agent DDS was dissolved into EPC at $130{ }^{\circ} \mathrm{C}$ with stirring; the mixture of EPC/DDS was poured into pre heated polytetrafluoroethylene (PTFE) molds. The cur ing temperature profile was set as $180^{\circ} \mathrm{C}$ for $2 \mathrm{~h}$ and $200{ }^{\circ} \mathrm{C}$ for $1 \mathrm{~h}$.

The preparations of EP/PM and EP/IC followed the same procedure as below. Firstly certain amounts (2, 4 and $6 \mathrm{wt} \%$ ) of PM or IC were dispersed into EPC at $170{ }^{\circ} \mathrm{C}$. Then the curing agent DDS was dissolved into EPC/PM and EPC/IC mixture at $130^{\circ} \mathrm{C}$. After DDS was totally dissolved by EPC, the final mixture was poured into pre heated polytetrafluoroethylene (PTFE) 

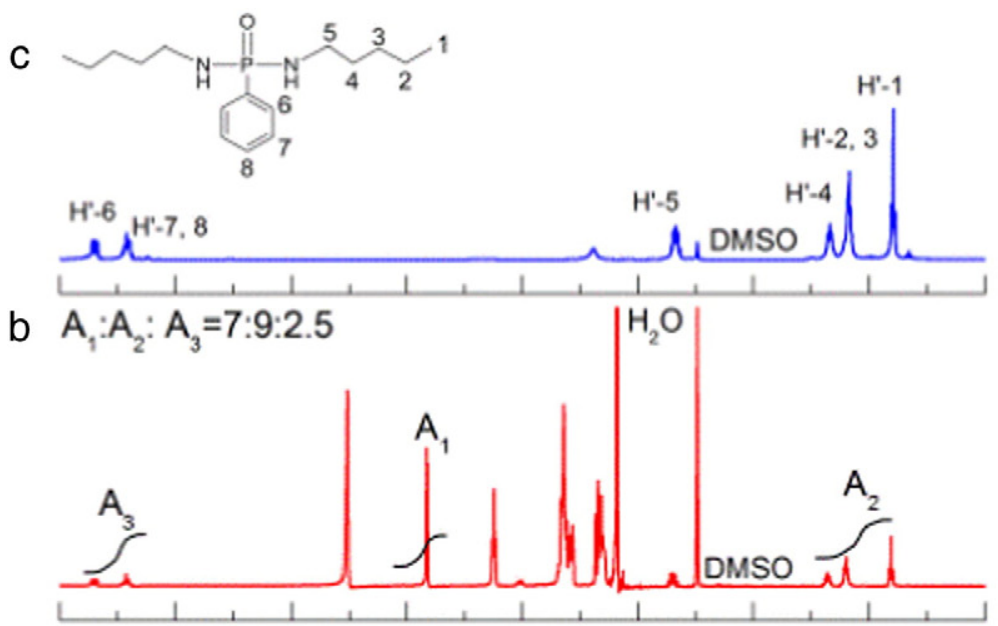

a
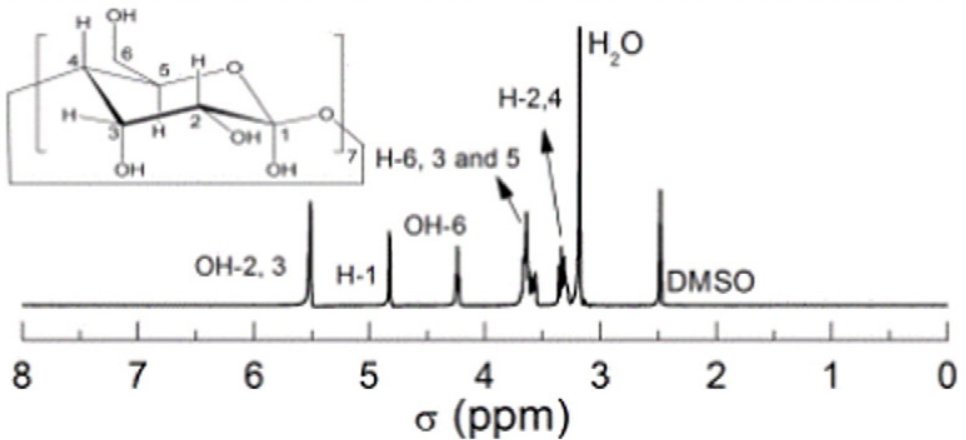

$f$

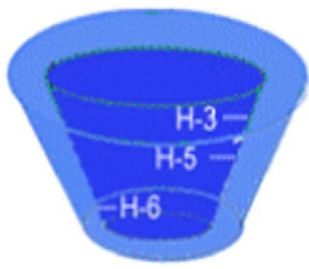

$H^{\prime}-1$

e

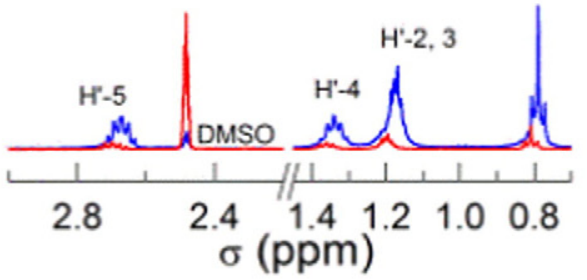

d

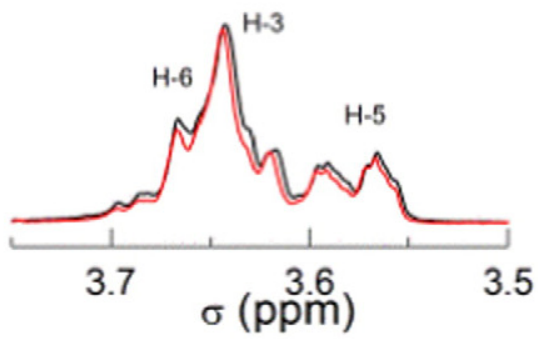

Fig. 1. ${ }^{1} \mathrm{H}$ NMR spectra of $\beta-C D(a)$, IC (b) and P-MA(c); enlarged ${ }^{1} \mathrm{H}$ NMR spectra of a, b and $c$; f, the structure of $\beta-C D$.

molds. The curing temperature profile was the same with that of EP. The formula of EP, EP/PM and EP/IC were listed in Table 1.

\subsection{Characterization}

\subsubsection{Nuclear magnetic resonance (NMR)}

NMR measurements were carried on Varian Mercury AS400 spec trometer which was operated at $400 \mathrm{MHz} .{ }^{1} \mathrm{H}$ NMR spectra was collect ed at room temperature by using tetramethylsilane (TMS) as internal standard and DMSO as the solvent.

\subsubsection{Fourier transform infrared spectrum (FTIR)}

The FTIR spectra of $\beta C D, P$ MA, PM of them and IC were measured with Nicolet iS50 infrared spectrometer. $\mathrm{KBr}$ pellet pressing method was used to prepare the samples. The scanning number and resolution of setting up were 16 and $4 \mathrm{~cm}^{-1}$.

\subsubsection{Wide angle $X$ ray diffraction (WAXD)}

PANalytical $X$ ray diffractometer was employed to perform WAXD measurements. The specific parameters for the measurements were as below: Ni filtered $\mathrm{Cu}$ Ka radiation source with $\lambda=1.544 \AA \AA$; scanning

Table 1

The formulations, Tg and results of LOI of EP, EP/PM and EP/IC.

\begin{tabular}{lccccc}
\hline Sample & EPC/DDS (wt\%) & PM (wt\%) & IC (wt\%) & $\operatorname{Tg}\left({ }^{\circ} \mathrm{C}\right)$ & LOI (\%) \\
\hline EP & 100 & - & - & 195 & 22.0 \\
EP/PM(2 wt\%) & 98 & 2 & - & 194 & 24.5 \\
EP/PM (4 wt\%) & 96 & 4 & - & 190 & 24.8 \\
EP/PM (6 wt\%) & 94 & 6 & - & 189 & 25.5 \\
EP/IC (2 wt\%) & 98 & - & 2 & 194 & 26.5 \\
EP/IC (4 wt\%) & 96 & - & 4 & 190 & 26.8 \\
EP/IC (6 wt\%) & 94 & - & 6 & 190 & 26.8 \\
\hline
\end{tabular}

range of $390^{\circ} / 2 \theta$ with a step size of $0.017^{\circ} ; 45 \mathrm{kV}$ and $40 \mathrm{~mA}$ of the voltage and current respectively.

\subsubsection{Differential scanning calorimeter (DSC)}

DSC (TA, Q200) measured the heat flow thermograms of $\beta C D, P M$, IC and P MA under nitrogen atmosphere. The solid sample pan was in use. $46 \mathrm{mg}$ of samples was examined at a heating rate of $10^{\circ} \mathrm{C} / \mathrm{min}$ during temperature range of $25350{ }^{\circ} \mathrm{C}$.

\subsubsection{Thermal gravimetric analysis (TGA)}

Thermal gravimetric analysis (TA, Q50) was performed under nitro gen atmosphere. The sample gas purge flow was $90 \mathrm{~mL} / \mathrm{min}$. $7.5 \pm$ $0.5 \mathrm{mg}$ of samples was tested over a temperature range from room tem perature to $700{ }^{\circ} \mathrm{C}$ at heating rate of $10{ }^{\circ} \mathrm{C} / \mathrm{min}$.

2.5.6. Scanning electron microscopy with $X$ ray microanalysis (SEM EDS)

SEM EDS (Zeiss, EVO MA15) measurement was conducted to ana lyze the morphology and distribution of element of $\beta$ CD and IC. The samples were coated with a fine gold layer under $20 \mathrm{kV}$ condition.

\subsubsection{Limiting oxygen index ( $\mathrm{LOI}$ )}

LOI tested on oxygen index meter (FTT) according to ASTM D2863 97. The precision of LOI test was $\pm 0.2 \%$. The sample size was $130 \times$ $6.5 \times 3.2 \mathrm{~mm}^{3}$.

\subsubsection{UL 94 test}

The Vertical burning tests were carried on a UL 94 Horizontal/Verti cal Flame Chamber (FTT, UK) and sheet dimensions of the samples were $130 \times 13 \times 3.2 \mathrm{~mm}^{3}$ according to ASTM D3801.

\subsubsection{Cone calorimeter test}

Cone calorimeter tests were carried out according to the ISO 56601 standard with a cone calorimeter (FTT). Square specimens $(100 \times 100 \times$ $4 \mathrm{~mm}^{3}$ ) were irradiated at a heat flux of $50 \mathrm{~kW} / \mathrm{m}^{2}$. 
Table 2

Chemical shifts and its variations for the protons of $\beta-\mathrm{CD}, \mathrm{P}-\mathrm{MA}$ in the free state and in the inclusion complex.

\begin{tabular}{lcccc}
\hline Proton & \multicolumn{4}{c}{$\sigma(\mathrm{ppm})$} \\
\cline { 2 - 5 } & $\beta-\mathrm{CD}$ & P-MA & IC & $\Delta \sigma\left(\sigma_{\text {complex }}-\sigma_{\text {free }}\right)$ \\
\hline $\mathrm{H}-3$ & 3.642 & - & 3.644 & 0.002 \\
$\mathrm{H}-5$ & 3.566 & - & 3.568 & 0.002 \\
$\mathrm{H}-6$ & 3.666 & - & 3.667 & 0.001 \\
$\mathrm{H}^{\prime}-1$ & - & 0.790 & 0.809 & 0.019 \\
$\mathrm{H}^{\prime}-(2,3)$ & - & 1.171 & 1.195 & 0.024 \\
$\mathrm{H}^{\prime}-4$ & - & 1.351 & 1.362 & 0.011 \\
$\mathrm{H}^{\prime}-5$ & - & 2.686 & 2.712 & 0.026 \\
$\mathrm{H}^{\prime}-6$ & - & 7.703 & 7.708 & 0.005 \\
$\mathrm{H}^{\prime}-7,8$ & - & 7.431 & 7.427 & 0.004 \\
\hline
\end{tabular}

\section{Results and discussion}

\subsection{Characterization of IC}

\subsection{1. ${ }^{1} \mathrm{H}$ NMR analysis}

As one of the frequently used tools to characterize the structure of inclusion complex, ${ }^{1} \mathrm{H}$ NMR spectroscopy is insightful to show the changes of chemical shift $(\sigma)$ of $\mathrm{H}$ protons on host and guest structures caused by the inclusion behavior [46 49]. The chemical shifts of $\mathrm{H} \mathrm{3,H}$ 5 and $\mathrm{H} 6$ protons inside the $\beta$ CD cavity (Fig. 1f) would show changes when P MA is embedded into the cavity. Fig. 1 showed the ${ }^{1} \mathrm{H}$ NMR spectra of $\beta \mathrm{CD}(\mathrm{a}), \mathrm{IC}(\mathrm{b})$ and $\mathrm{P}$ MA(c). Table 2 listed the $\sigma$ of $\beta \mathrm{CD}$, IC and P MA. $\triangle \sigma$ were calculated as the differences between $\sigma$ of IC $\left(\sigma_{\text {complex }}\right)$ and $\sigma$ of $\beta$ CD or IC $\left(\sigma_{\text {free }}\right)$.

After the inclusion behavior, $\sigma$ of $\mathrm{H} 3, \mathrm{H} 5$ and $\mathrm{H} 6$ protons inside the $\beta$ CD cavity shifted to upfield by $0.002,0.002$ and $0.001 \mathrm{ppm}$, re spectively. All $\sigma$ of $H$ protons of P MA showed upfield shifts. The $\Delta \sigma$ of $\beta C D$ and $P$ MA in Table 2 indicated that $P$ MA was evidently embedded into the cavity of $\beta C D$. Furthermore, $\Delta \sigma$ of $\mathrm{H}^{\prime} 1, \mathrm{H}^{\prime}(2,3), \mathrm{H}^{\prime} 4$ and $\mathrm{H}^{\prime} 5$ on alkyl chain of P MA were $0.019,0.024,0.011,0.026$ ppm respectively, which were much further than $\Delta \sigma$ of $\mathrm{H}^{\prime} 6$ and $\mathrm{H}^{\prime}(7,8)$ on benzene ring of P MA. It indicated that inclusion behavior might occur mainly be tween the alkyl chains of $P$ MA and $\beta$ CD cavity.

In addition, the integral area ratios of $\mathrm{H} 1$ of $\beta \mathrm{CD}\left(\mathrm{A}_{1}\right), \mathrm{H}^{\prime}$ benzene ring $\left(A_{2}\right)$ and $H^{\prime}(1,2,3$ and 4$)\left(A_{3}\right)$ was 7:9:2.5, indicating that one $P$ MA molecule was included with two $\beta$ CD molecules. It meant the molar ratio between $\beta$ CD and P MA was 1:0.5 in IC. The possible IC structures were showed in Fig. $2 \mathrm{a}$ and $\mathrm{b}$. The inclusion behavior oc curred between alkyl chain and $\beta \mathrm{CD}$ was considered to start from the wide side of $\beta$ CD owing to the higher $\sigma$ of $\mathrm{H} 3$ and $\mathrm{H} 5$ than that of H 6.

\subsubsection{FTIR analysis}

FTIR spectroscopy is a common measurement to characterize the molecular structure due to the infrared vibrations of functional groups. In this study, FTIR was used to show the inclusion behavior between $\beta$ CD and P MA. Fig. 3 showed the FTIR spectra of $\beta$ CD, IC, PM and P MA.

The assignments of main IR peaks of $\beta \mathrm{CD}$ were: $3380 \mathrm{~cm}^{-1}(-\mathrm{OH})$; $2828 \mathrm{~cm}^{-1}$ (C-H of $-\mathrm{CH}_{2}$ and $\left.-\mathrm{CH}\right) ; 1080,1028 \mathrm{~cm}^{-1}$ (C-O-C); $1159 \mathrm{~cm}^{-1}(\mathrm{C}-\mathrm{C})$; 756, $707 \mathrm{~cm}^{-1}$ (skeleton of $\beta \mathrm{CD}$ ). The assignments of main IR peaks of P MA were: $3200 \mathrm{~cm}^{-1}(\mathrm{~N}-\mathrm{H}) ; 3055 \mathrm{~cm}^{-1}(\mathrm{C}-\mathrm{H}$ of benzene ring); 2956, $2863 \mathrm{~cm}^{-1}\left(\mathrm{C}-\mathrm{H}\right.$ of $\left.-\mathrm{CH}_{3}\right) ; 2932,2875 \mathrm{~cm}^{-1}$ $\left(\mathrm{C}-\mathrm{H}\right.$ of $\left.-\mathrm{CH}_{2}\right) ; 1627,1542,1469$ and $1436 \mathrm{~cm}^{-1}$ ( $\mathrm{C}-\mathrm{C}$ of benzene ring); $1180 \mathrm{~cm}^{-1}(\mathrm{P}=0) ; 1129 \mathrm{~cm}^{-1}(\mathrm{C}-\mathrm{N}) ; 1025,730 \mathrm{~cm}^{-1}$ $(\mathrm{P}-\mathrm{N}) ; 924 \mathrm{~cm}^{-1}(\mathrm{P}-\mathrm{N}-\mathrm{C}) ; 752,696 \mathrm{~cm}^{-1}$ (benzene ring). Com pared with the spectra of $\beta$ CD and P MA, both the spectra of PM and IC showed the similar outline with the spectrum of $\beta C D$ rather than that of P MA. The reasons were that the molar ratio of IR groups of $\beta$ $C D$ was much higher than that of IR groups of P MA and the IR peaks of $\beta$ CD overlapped with most of IR peaks of P MA.

Nevertheless, the spectra of PM and IC showed specific differences. The frequency ranges of $31002700 \mathrm{~cm}^{-1}, 15501350 \mathrm{~cm}^{-1}$ and $810660 \mathrm{~cm}^{-1}$ were enlarged and shown as a, b and c, respectively in Fig. 3. In Fig. 3a, the peaks at 2863 and $2875 \mathrm{~cm}^{-1}$ of P MA showed at the same peak position in spectra of PM, while these two peaks were very weak and almost did not show in spectra of IC. In Fig. 3b, the peak at $1436 \mathrm{~cm}^{-1}$ in spectra of P MA did not shift in the spectra of
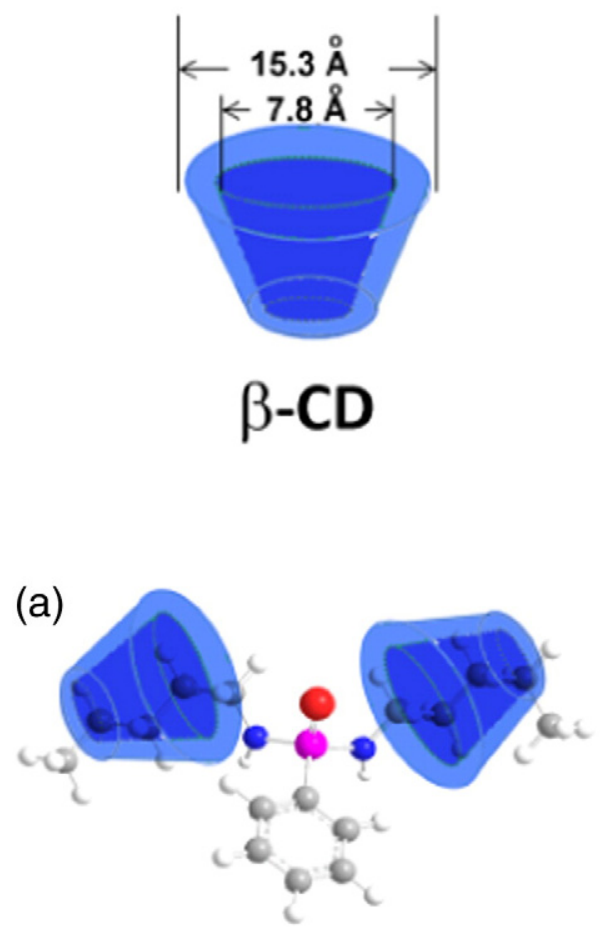
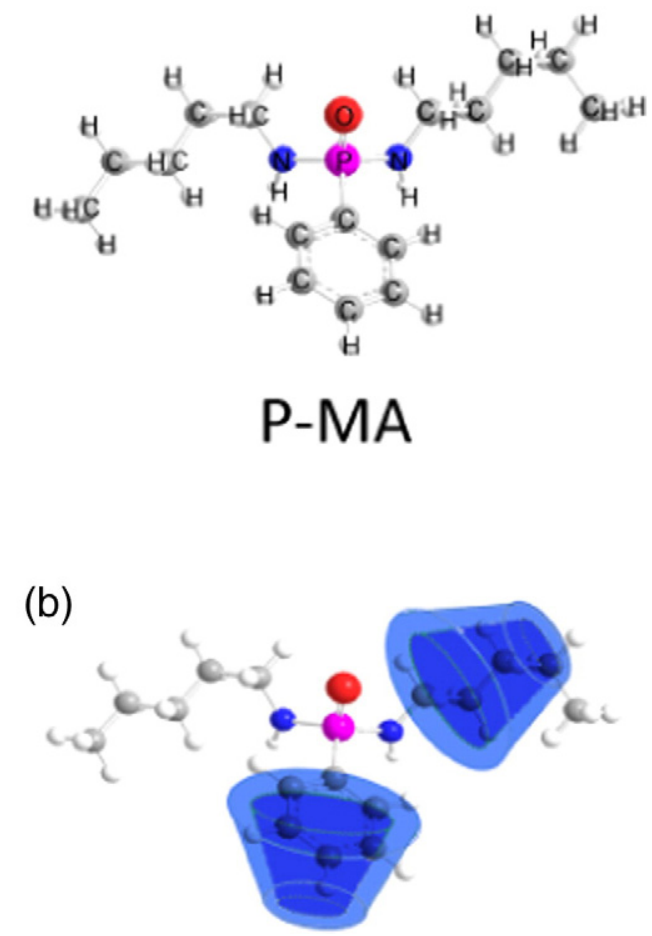

Fig. 2. The possible structures of IC ( $a$ and $b)$. 

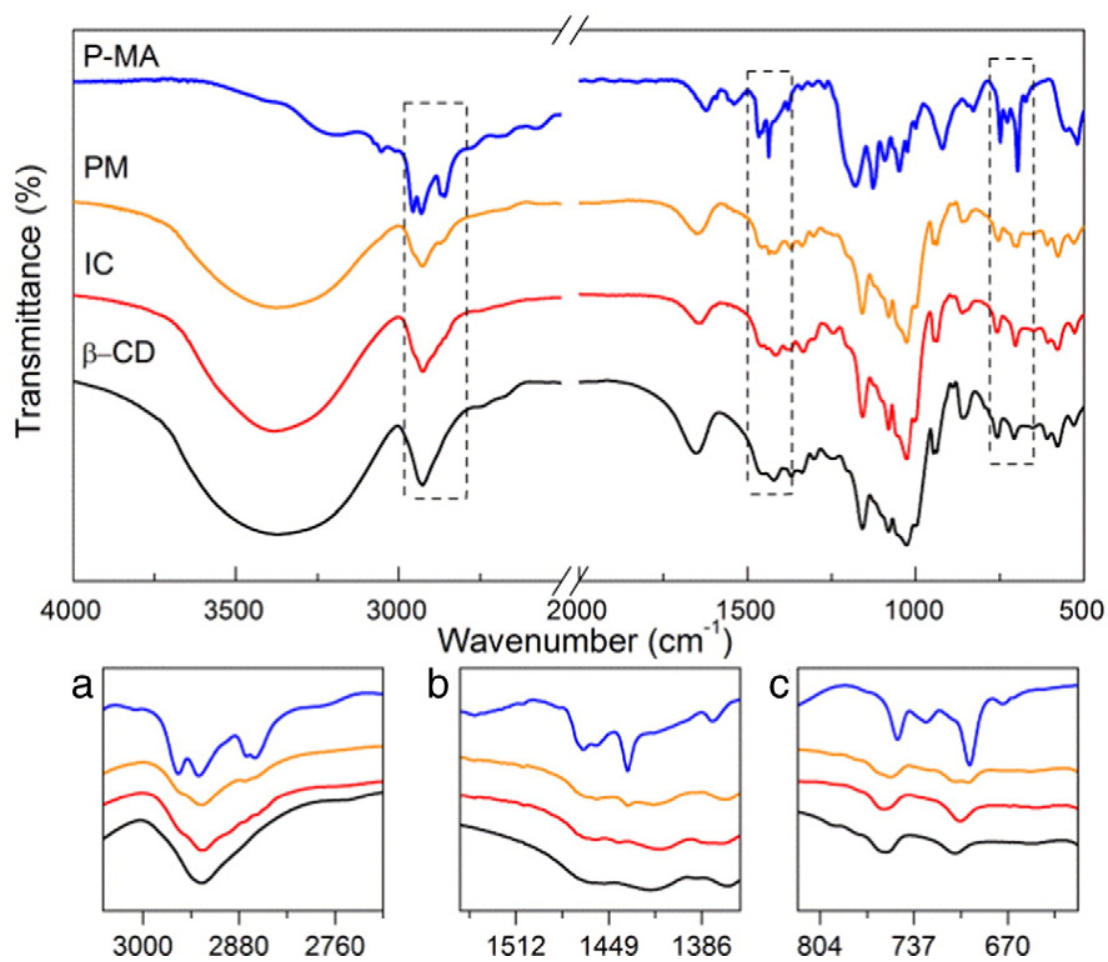

Fig. 3. FTIR spectra of $\beta-C D$, IC, PM and P-MA

PM, while it shifted to $1442 \mathrm{~cm}^{-1}$ in spectra of IC. In addition, the peak of $P$ MA at $696 \mathrm{~cm}^{-1}$ simply combined with the peak of $\beta C D$ at 707 $\mathrm{cm}^{-1}$ in spectra of PM, showing as a broad peak in Fig. 3c. These two peaks merged to be one at $703 \mathrm{~cm}^{-1}$ in the spectrum of IC. Fig. 3a indi cated the change of chemical environment of alky chain of P MA. Mean while, Fig. $3 b$ and $c$ showed the changes of chemical environment of benzene ring of P MA. All the above changes indicated that P MA was successfully embedded into the cavity of $\beta \mathrm{CD}$.

\subsubsection{XRD analysis}

$\mathrm{X}$ ray diffraction (XRD) is a widely used method to study the inclu sion complex. In general, the diffraction peaks of host and guest mole cules are changed after the inclusion behavior [49 51]. In this study, the comparison of XRD spectra as shown in Fig. 4(a) was done between $\beta C D$ and IC. Fig. 4(a) showed the XRD spectra of $\beta C D$ under two con ditions: one was the spectra after treated by inclusion procedure with out P MA; the other one was the spectra without any treatment. The diffraction spectra of $\beta C D$ before and after treatment showed that the crystalline phase of $\beta C D$ was changed due to the re crystallization. The main peak at $12.3^{\circ}$ was getting sharper and the intensities of peaks at 8.8 and $10.5^{\circ}$ were higher, indicating that the crystal of $\beta C D$ was changed after the treatment. In comparison with the above two XRD spectra of $\beta C D$, IC showed a totally different spectra. The diffrac tion peaks was broader and the number of peaks was less than those of $\beta C D$ before and after the treatment. Three main peaks were at 5.8, 11.6 and $18.1^{\circ}$. These differences indicated that new compound formed during inclusion procedure. It was another evidence to verify the success of inclusion behavior.
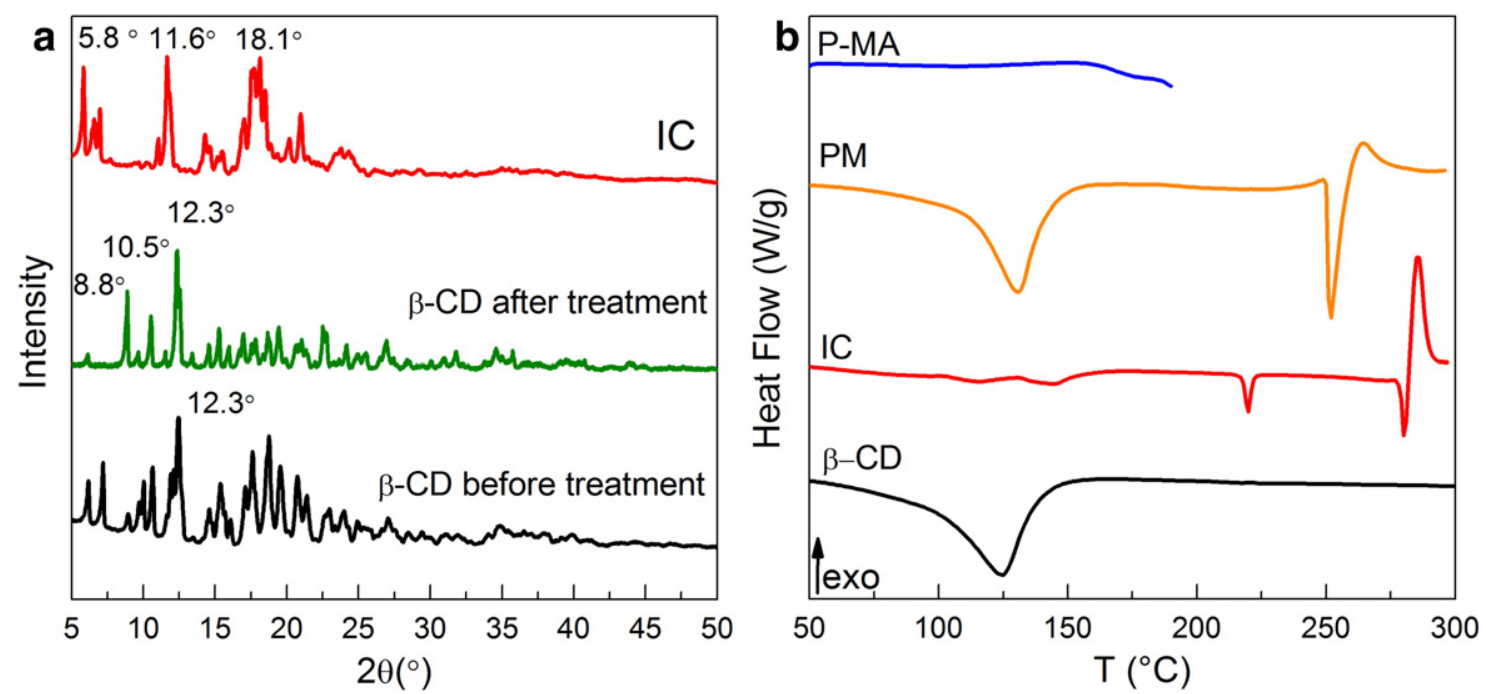

Fig. 4. a XRD spectra of $\beta-C D$ and IC; $b$, DSC curves of $\beta-C D$, IC, PM and P-MA under $N_{2}$. 


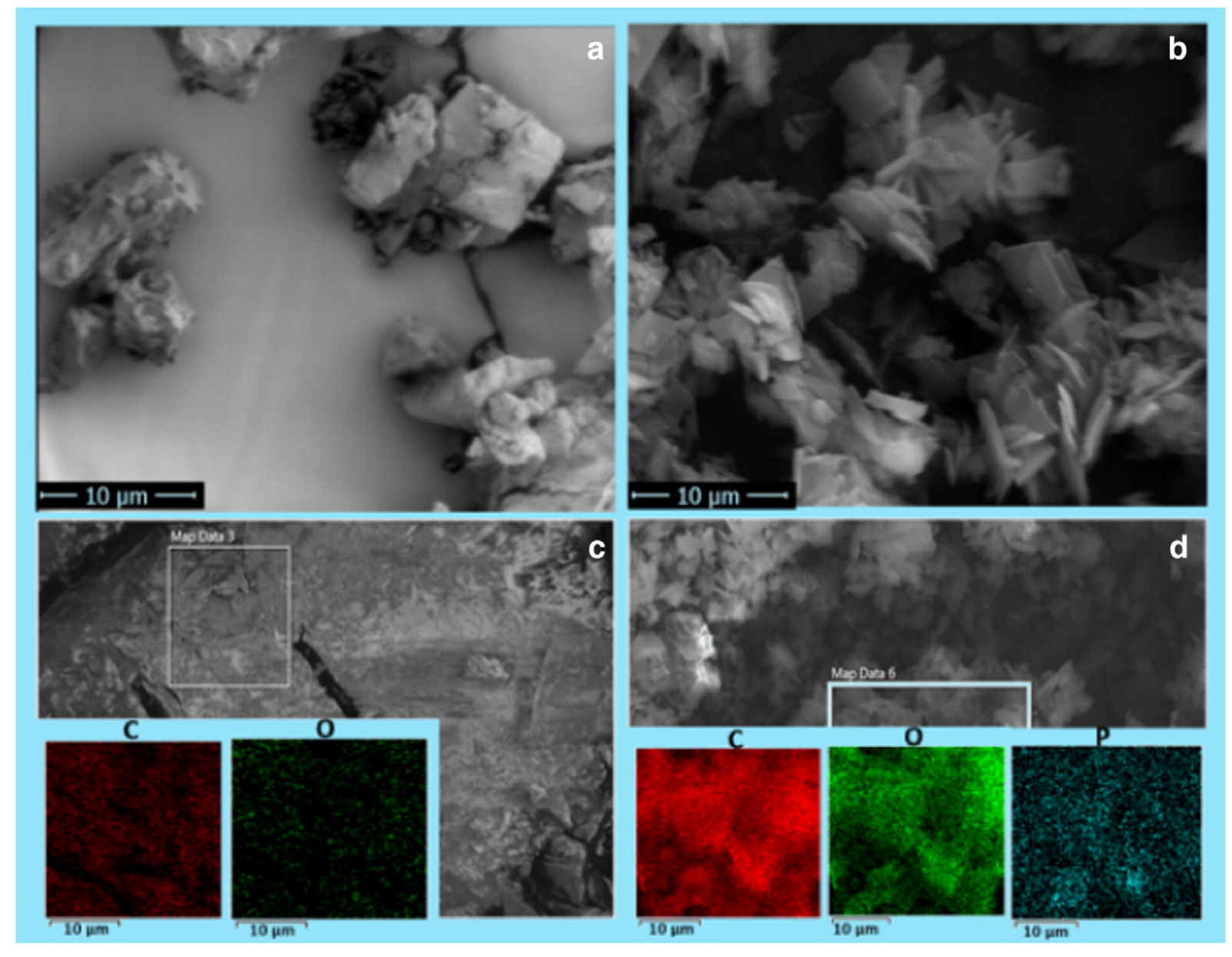

Fig. 5. SEM and element distribution mapping images of $\beta-C D(a, c)$ and $I C(b, d)$.

\subsubsection{DSC analysis}

Seen from the heat flow curves in Fig. 4(b), $\beta$ CD showed a broad en dothermic peak around $125{ }^{\circ} \mathrm{C}$ caused by the dehydration reaction. There was no other peak appeared before $300{ }^{\circ} \mathrm{C}$. As to P MA, there was no significant peak showed before $180^{\circ} \mathrm{C}$. Compared with $\beta \mathrm{CD}$ and P MA, the physical mixture (PM) of them showed a different DSC curve. The dehydration peak of $\beta \mathrm{CD}$ was still existed, while the decom position temperature shifted to the low temperature around $253^{\circ} \mathrm{C}$. The reason was that the acid compounds formed during thermal decompo sition of P MA were able to accelerate the decomposition of $\beta$ CD. In contrast, IC showed totally different curve compared with the above three samples. Firstly, the endothermic peak around $125^{\circ} \mathrm{C}$ was weak ened remarkably, indicating the dehydration effect of IC was weaker than those of $\beta \mathrm{CD}$ and PM. The decomposition of IC occurred at around $280^{\circ} \mathrm{C}$, which was higher than that of PM, but lower than that of $\beta \mathrm{CD}$. This information showed that IC was not physically mixed during the in clusion procedure, indicating that the inclusion behavior between $\beta C D$ and P MA was succeeded.

\subsubsection{Morphological analysis}

SEM EDS is a useful tool to characterize the morphology and detect the element types on the sample surface [52]. After the inclusion behav ior, the morphologies of $\beta C D$ and IC are supposed to be different with each other. In addition, phosphorous element should be detected only in IC.

Fig. 5a and b were SEM images of $\beta$ CD and IC, respectively. Com pared with the large particle size and shape of $\beta C D$, IC showed small and irregular lamella particles. Fig. $5 \mathrm{c}$ and $\mathrm{d}$ were the element distribution mapping of $\mathrm{C}, \mathrm{O}$ and $\mathrm{P}$ of $\beta \mathrm{CD}$ and $\mathrm{IC}$ respectively. The map ping areas of $\beta C D$ and IC were marked respectively in the SEM images with white frame. From Fig. 5, there was no detection of phosphors ele ment in $\beta C D$, while phosphorus element was obviously showed in IC and the distribution was kept the same state with those of $C$ and $O$ ele ments. These results further indicated the inclusion behavior between $\beta C D$ and P MA was succeeded.

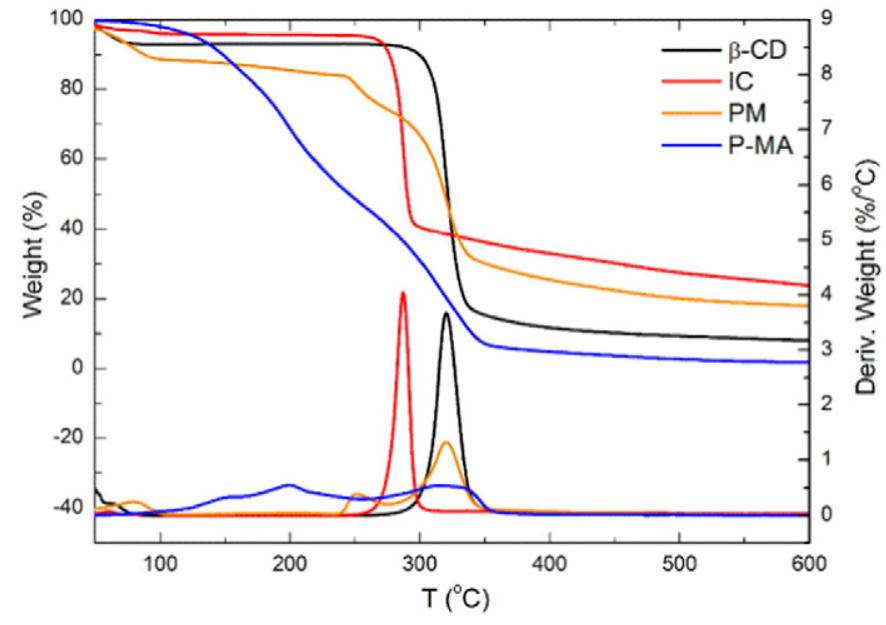

Fig. 6. TGA and DTG curves of $\beta-C D, I C, P M$ and $P-M A$ under $N_{2}$. 

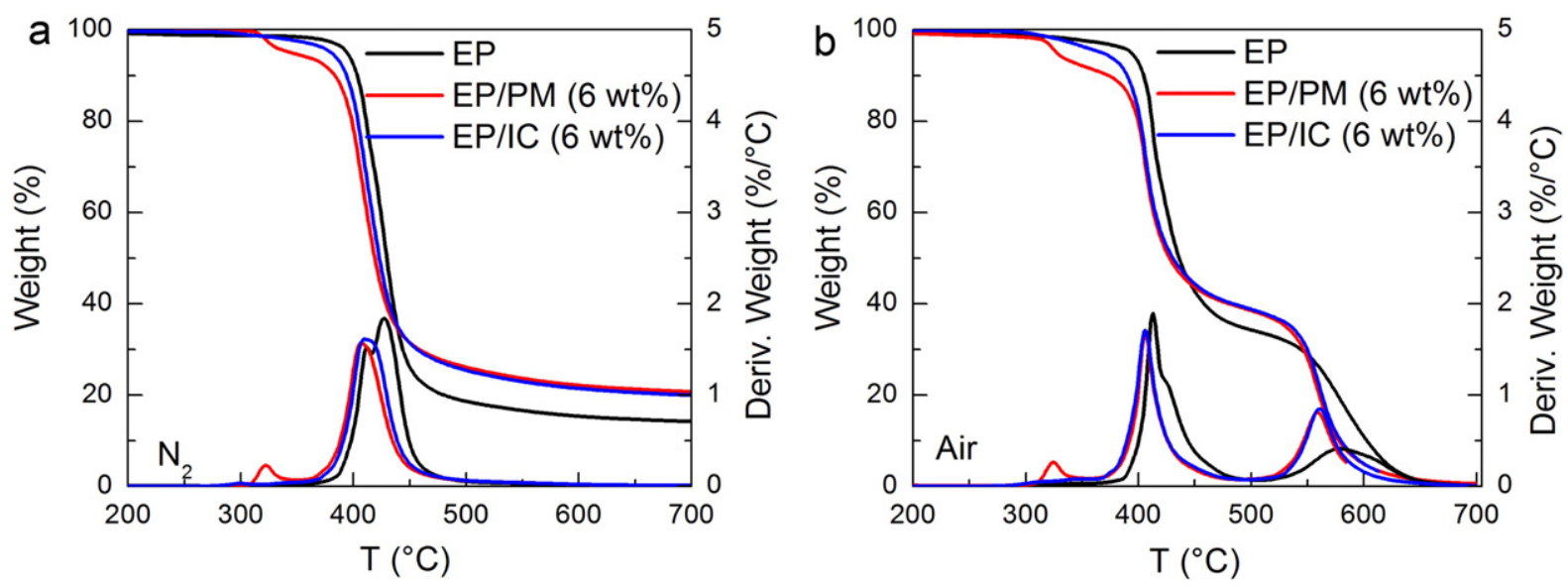

Fig. 7. TGA and DTG curves of EP, EP/PM (6 wt\%) and EP/IC (6 wt\%) under $\mathrm{N}_{2}$ (a) and under air (b).

\subsection{Impact of IC on thermal stability of EP}

The thermal stability of $\beta$ CD, P MA, PM and IC were compared by TGA under nitrogen $\left(\mathrm{N}_{2}\right)$. Fig. 6 showed the TGA curves of $\beta C D, P$ $\mathrm{MA}, \mathrm{PM}$ and IC under $\mathrm{N}_{2}$. The thermal and thermo oxidative stability of EP, EP/PM and EP/IC were studied by TGA under $\mathrm{N}_{2}$ and air respec tively. Fig. 7 showed TGA and DTG curves of EP, EP/PM (6 wt\%) and $\mathrm{EP} / \mathrm{IC}$ (6 wt\%) under $\mathrm{N}_{2}$ (a) and under air (b). The TGA data of EP, EP/ PM (2, 4 and $6 \mathrm{wt} \%)$ and $\mathrm{EP} / \mathrm{IC}(2,4$ and $6 \mathrm{wt} \%)$ were shown in Table 3.

In Fig. 6 , the initial decomposition temperature of $\beta \mathrm{CD}$ was around $270{ }^{\circ} \mathrm{C}$, while flame retardant P MA showed remarkable weight loss from $100{ }^{\circ} \mathrm{C}$ to $200{ }^{\circ} \mathrm{C}$. On DTG curve, $\beta$ CD showed one peak around $320^{\circ} \mathrm{C}$. P MA showed a broad low decomposition peak on DTG curve. PM started to decompose since around $220^{\circ} \mathrm{C}$, while the initial thermal decomposition of IC occurred above $250^{\circ} \mathrm{C}$. Compared with $\beta \mathrm{CD}$, ther mal decomposition of PM showed two peaks on DTG curves. One peak was at $257^{\circ} \mathrm{C}$, the other peak was at $320^{\circ} \mathrm{C}$. The first peak was caused by the decomposition of $\mathrm{P}$ MA and then the decomposition of $\beta C D$ was induced. In contrast, IC showed one step decomposition. The decomposing peak appeared at $270{ }^{\circ} \mathrm{C}$ which was also different with that of $\beta$ CD. Both PM and IC showed higher char residue amounts com pared with $\beta \mathrm{CD}$ and $\mathrm{P}$ MA at $600{ }^{\circ} \mathrm{C}$. The residue of PM was $16.8 \%$, while those of $\beta$ CD and P MA were 8.1 and $2.2 \%$, respectively. The in crease of residue amount for PM and IC was due to the catalytic effect of acid compounds produced from the thermal decomposition of $\mathrm{P}$ MA. IC showed a higher residue amount (25.9\%) than that of PM, indi cating that the catalytic effect of P MA was enhanced via inclusion be havior. Above analysis illustrated that IC showed enhanced thermal stability compared with PM and P MA; IC showed better charring ability compared with $\beta \mathrm{CD}, \mathrm{PM}$ and P MA.

Table 3

TGA data of EP, EP/PM and EP/IC under $\mathrm{N}_{2}$ and air.

\begin{tabular}{|c|c|c|c|c|c|c|c|c|c|}
\hline \multirow[t]{2}{*}{ Samples } & \multicolumn{2}{|c|}{$\begin{array}{l}\mathrm{T}_{\mathrm{d} 5 \%}{ }^{\mathrm{a}} \\
\left({ }^{\circ} \mathrm{C}\right)\end{array}$} & \multicolumn{2}{|c|}{$\begin{array}{c}\mathrm{T}_{\max 1}{ }^{\mathrm{b}} \\
\left({ }^{\circ} \mathrm{C}\right)\end{array}$} & \multicolumn{2}{|c|}{$\begin{array}{c}\mathrm{T}_{\max 2}{ }^{\mathrm{c}} \\
\left({ }^{\circ} \mathrm{C}\right)\end{array}$} & \multirow{2}{*}{$\frac{\begin{array}{c}\mathrm{T}_{\max 3}{ }^{\mathrm{d}} \\
\left({ }^{\circ} \mathrm{C}\right)\end{array}}{\text { Air }}$} & \multicolumn{2}{|c|}{$\begin{array}{c}\text { Residue } \\
\left(700^{\circ} \mathrm{C}, \%\right)\end{array}$} \\
\hline & $\mathrm{N}_{2}$ & Air & $\mathrm{N}_{2}$ & Air & $\mathrm{N}_{2}$ & Air & & $\mathrm{N}_{2}$ & Air \\
\hline EP & 394 & 392 & 427 & 412 & - & 580 & - & 14.4 & 0 \\
\hline EP/PM (2 wt\%) & 386 & 378 & 328 & 333 & 418 & 411 & 573 & 17.9 & 0 \\
\hline $\mathrm{EP} / \mathrm{PM}$ (4 wt\%) & 370 & 362 & 330 & 329 & 414 & 406 & 570 & 19.9 & 0 \\
\hline $\mathrm{EP} / \mathrm{PM}$ (6 wt\%) & 344 & 327 & 322 & 323 & 408 & 405 & 559 & 21.6 & 0 \\
\hline $\mathrm{EP} / \mathrm{IC}$ (2 wt\%) & 390 & 386 & 423 & 411 & - & 573 & - & 17.8 & 0 \\
\hline $\mathrm{EP} / \mathrm{IC}$ (4 wt\%) & 380 & 376 & 415 & 406 & - & 570 & - & 21.5 & 0 \\
\hline $\mathrm{EP} / \mathrm{IC}$ (6 wt\%) & 380 & 366 & 412 & 406 & - & 560 & - & 21.5 & 0 \\
\hline
\end{tabular}

a $T_{d 5 \%}$ meant the temperature when the weight loss was $5 \%$.

$\mathrm{T}_{\max 1}$ meant the first peak $\mathrm{T}$ at maximum decomposition rate.

c $\mathrm{T}_{\max 2}$ meant the second peak $\mathrm{T}$ at maximum decomposition rate.

d $\mathrm{T}_{\max 3}$ meant the third peak $\mathrm{T}$ at maximum decomposition rate.
In Fig. 7(a), the thermal decomposition of EP went though one stage decomposition. $\mathrm{T}_{\mathrm{d} 5 \%}$ and $\mathrm{T}_{\max }$ of EP were at $394{ }^{\circ} \mathrm{C}$ and at $427{ }^{\circ} \mathrm{C}$ respec tively. The residue amount was $14.4 \%$ at $700^{\circ} \mathrm{C}$. With regard to $\mathrm{EP} / \mathrm{PM}$, PM showed significant impact on thermal decomposition of EP. $\mathrm{T}_{\mathrm{d} 5 \%}$ was lowered greatly along with the rising of PM loading in EP. For in stance, $\mathrm{T}_{\mathrm{d} 5 \%}$ of EP/PM (6 wt\%) was at $344{ }^{\circ} \mathrm{C}$ which was $50{ }^{\circ} \mathrm{C}$ lower than that of EP. From $300{ }^{\circ} \mathrm{C}$ to $550{ }^{\circ} \mathrm{C}, \mathrm{EP} / \mathrm{PM}$ went through two stage decomposition. The first DTG peak was considered to be induced by thermal decomposition of P MA in EP. $\mathrm{T}_{\max 1} \mathrm{~S}$ of EP/PM $(2,4$ and $6 \mathrm{wt} \%$ ) were at 328,330 and $322{ }^{\circ} \mathrm{C}$ respectively. The second DTG peaks of EP/PM were the main decomposition peak. $\mathrm{T}_{\max 2} \mathrm{~S}$ of EP/PM were at lower temperature than $\mathrm{T}_{\max 1}$ of $\mathrm{EP}$, showing that the addition of PM accelerated the decomposition of EP. $\mathrm{T}_{\max 2}$ of EP/PM ( $6 \mathrm{wt} \%$ ) was at $408{ }^{\circ} \mathrm{C}$ which was $19{ }^{\circ} \mathrm{C}$ lower than $\mathrm{T}_{\max 1}$ of EP. The residue amounts were increased from $14.4 \%$ to $17.9,19.9$ and $21.6 \%$ at 2,4 and 6 wt\% loading of PM in EP. Compared with PM, the impact of IC was not as sig nificant as that of PM on thermal decomposition of EP. $\mathrm{T}_{\mathrm{d} 5 \%} \mathrm{~S}$ of EP/IC $(2$, 4 and $6 \mathrm{wt} \%$ ) were at 390,380 and $380{ }^{\circ} \mathrm{C}$ respectively, which were higher than those of EP/PM at the same loading. DTG curves of EP/IC showed one peak as well as that of EP. $\mathrm{T}_{\max 1} \mathrm{~S}$ of EP/IC were between those of EP and EP/PM at the same loading. $\mathrm{T}_{\max 2}$ of EP/IC (6 wt\%) was at $412{ }^{\circ} \mathrm{C}$. The residue amounts of $\mathrm{EP} / \mathrm{IC}(2,4$ and $6 \mathrm{wt} \%)$ were 17.8 , 21.5 and $21.5 \%$ at $700{ }^{\circ} \mathrm{C}$ which were close to that of EP/PM with the same loading. Above all, the thermal stability of EP/IC was between those of EP/PM and EP. The residue amounts of EP/IC were close to EP/ PM.

In Fig. 7(b), thermal oxidative behavior of EP showed a two stage TGA curve under air. $\mathrm{T}_{\mathrm{d} 5 \%}$ of EP was at $392{ }^{\circ} \mathrm{C} . \mathrm{T}_{\max 1}$ and $\mathrm{T}_{\max 2}$ of EP were at 412 and $580{ }^{\circ} \mathrm{C}$, respectively. There were almost no residues remained at $700{ }^{\circ} \mathrm{C}$ for all samples. EP/IC showed two stage TGA curves under air as well as EP. $\mathrm{T}_{\mathrm{d} 5 \%} \mathrm{~S}$ of EP/IC (2, 4 and $\left.6 \mathrm{wt} \%\right)$ were at 386, 376 and $366^{\circ} \mathrm{C}$, respectively, which were lower than that of EP. This result was induced by the thermal oxidation of IC. $\mathrm{T}_{\max 1}$ and $\mathrm{T}_{\max 2}$ of EP/IC shifted to lower temperatures. The maximum mass loss rate of the first peak on DTG curve of EP/IC was lower than that of EP. With regard to the second DTG peak, the maximum mass loss rate of EP/IC was higher than that of EP as shown in Fig. 7(b). It showed that the residues of EP/IC were not as stable as those of EP which were formed. At $700{ }^{\circ} \mathrm{C}$, no residue was left to EP/IC. Unlike EP and EP/IC, EP/PM showed three stage TGA curves as shown in Fig. 7(b). $\mathrm{T}_{\mathrm{d} 5 \%}$ of EP/PM showed at lower temperatures in comparison with $\mathrm{EP} / \mathrm{IC}$. This trend increased as the PM loading was increased in EP. For example, $\mathrm{T}_{\mathrm{d} 5 \%}$ of EP/PM ( $6 \mathrm{wt} \%$ ) was $327{ }^{\circ} \mathrm{C}$ which was $39{ }^{\circ} \mathrm{C}$ lower than that of EP/IC ( $\left.6 \mathrm{wt} \%\right) . \mathrm{T}_{\max 1}$ of EP/ PM (2, 4 and 6 wt\%) showed at relatively low temperatures $(333,329$ and $323^{\circ} \mathrm{C}$ respectively) as well, caused by the thermal oxidation of $\mathrm{P}$ MA in EP. The acidic compounds from P MA were able to accelerate the thermal oxidation of EP matrix. The second and third peaks on 
DTG curves of EP/PM were quite similar with those peaks on DTG curves of EP/IC as shown in Fig. 7(b). Above all, TGA results under air mainly showed that IC and PM showed a different impact on the thermal oxi dative behavior of EP at the initial stage.

Overall, the thermal stability of P MA was improved and the residue amount of $\beta C D$ was increased via inclusion process according to the comparison between IC and PM. The thermal stability of EP/IC was im proved compared with EP/PM with the same loading. Both EP/IC and EP/PM showed a higher residue amount compared with EP under $\mathrm{N}_{2}$, but no residue was kept at $700{ }^{\circ} \mathrm{C}$ under air as well as EP.

\subsection{Impact of IC on flame retardancy of EP}

\subsubsection{LOI and UL 94 tests}

LOI and UL 94 tests were two typical small scale tests to evaluate the flammability of polymer materials. LOI test measured the minimum concentration of oxygen in a flowing mixture of oxygen and nitrogen that can support flaming combustion of polymer materials. Table 1 showed LOI results of EP, EP/PM and EP/IC. The addition of PM increased LOI of EP from $22 \%$ to $24.5 \%$ at 2 wt $\%$ loading. When the loading rose to $6 \mathrm{wt} \%$, LOI of EP/PM was 25.5\%. The results showed that PM reduced the flammability of EP and this impact was proportional with the loading of PM. LOI of EP/IC ( $2 \mathrm{wt} \%$ ) was $26.5 \%$ which was 2 units higher than that of $\mathrm{EP} / \mathrm{PM}(2 \mathrm{wt} \%)$. The increase of LOI was not proportional with the IC loading in EP. LOI of EP/IC ( 4 and 6 wt\%) were $26.8 \%$ respectively which was very close to that of EP/IC (2 wt\%). The flammability of EP/ IC was lower compared with those of EP and EP/PM in LOI test. UL 94 test was used to determine the fire performance for the samples. As well as EP, both EP/PM and EP/IC showed no rating in UL 94 test. The re sults showed that PM and IC did not show a direct impact on the im provement of self extinguishing ability of EP at a loading range from 2 to $6 \mathrm{wt} \%$. The possible reason might be corresponding to the mass load ing of P MA used in epoxy matrix that was too low to reduce fire prop agation ability of EP. Since the mass loading of P MA in PM and/or IC was $11.5 \mathrm{wt} \%$, at the loading range from 2 to $6 \mathrm{wt} \%$ of PM or IC in EP, the mass loading of P MA in EP was only ranged from 0.23 to $0.69 \mathrm{wt} \%$. Such load ings of P MA may be too low for EP to pass some classification in UL94 test.

\subsubsection{Cone calorimeter test}

By using heat release equipment, as the cone calorimeter, the differ ent parameters (such as material ignitability, heat release and smoke production) can be measured in the same instrument, in a manner gen erally relevant to real fires [53]. Fig. 8 illustrated the characteristic curves of EP, EP/PM ( $6 \mathrm{wt} \%$ ) and EP/IC ( $6 \mathrm{wt} \%$ ) under $50 \mathrm{~kW} / \mathrm{m}^{2}$ from cone calorimeter test: a, HRR vs time; b, weight vs time; c, THR (total heat release) vs time and d, TSP (total smoke production) vs time. The related data from this test were collected in Table 4. TTI meant time to ignition and pHRR meant peak of HRR. Fig. 9 showed the carbon monox ide $(\mathrm{CO}) /$ carbon dioxide $\left(\mathrm{CO}_{2}\right)$ ratio curves of releasing rate of EP, EP/PM (6 wt\%) and EP/IC (6 wt\%).

Compared with TTI of EP (at $59 \pm 5$ s), TTIs of EP/PM and EP/IC were at earlier time. For instance, TTIs of EP/PM ( 6 wt\%) and EP/IC (6 wt\%) were at $54 \pm 3 \mathrm{~s}$ and $50 \pm 2 \mathrm{~s}$ respectively. In the condition of same
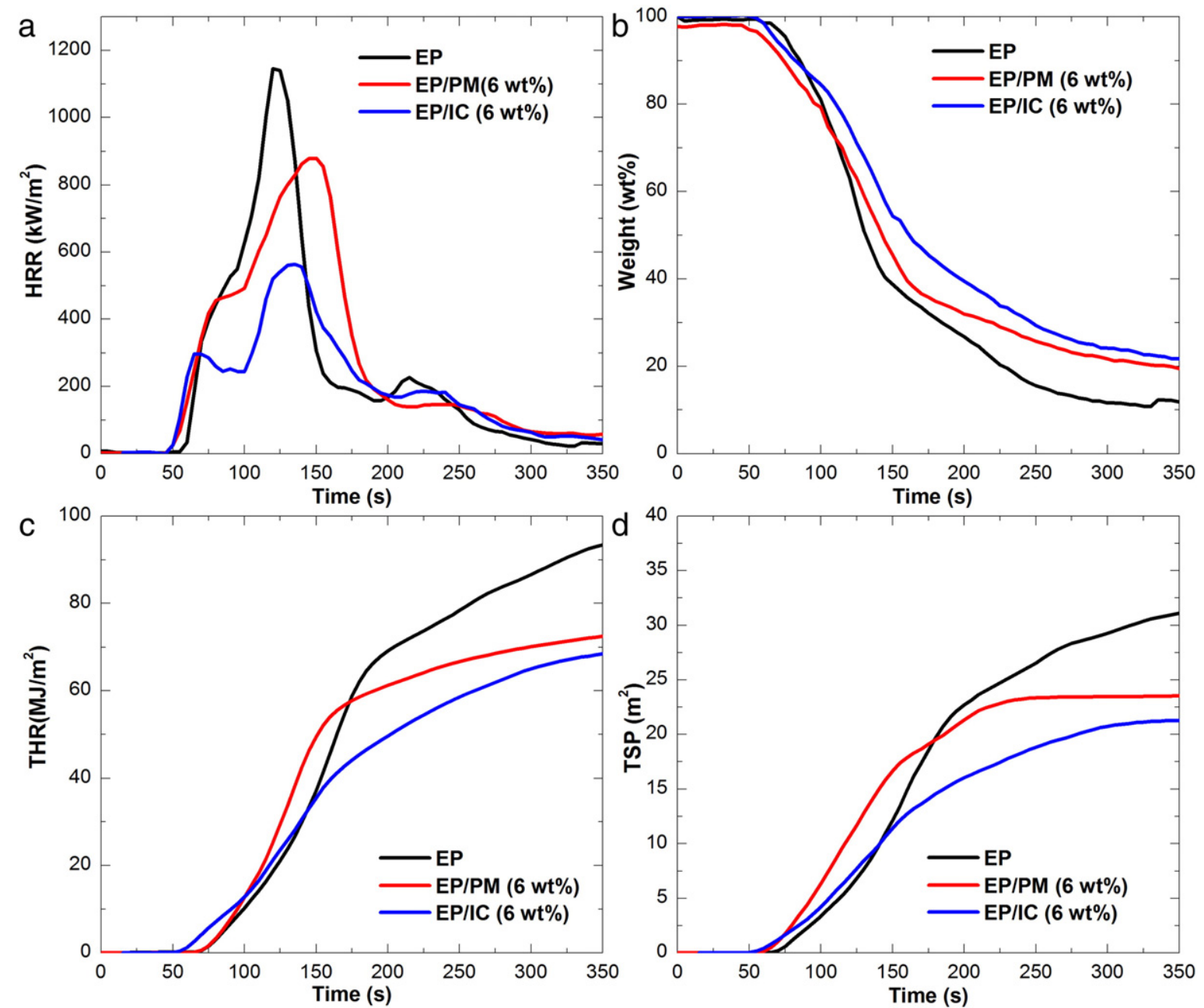

Fig. 8. a, HRR vs time; b, mass loss vs time; c, THR (total heat release) vs time and d, TSP (total smoke production) vs time curves of EP, EP/PM and EP/IC from cone calorimeter test. 
Table 4

The data from cone calorimeter test of EP, EP/PM and EP/IC at a heat flux of $50 \mathrm{~kW} / \mathrm{m}^{2}$.

\begin{tabular}{|c|c|c|c|c|c|c|}
\hline Sample & $\mathrm{TTI}^{\mathrm{a}}(\mathrm{s})$ & $\mathrm{pHRR}^{\mathrm{b}}\left(\mathrm{kW} / \mathrm{m}^{2}\right)$ & $\operatorname{THR}^{\mathrm{c}}\left(\mathrm{MJ} / \mathrm{m}^{2}\right)$ & $\mathrm{EHC}^{\mathrm{d}}(\mathrm{kJ} / \mathrm{kg})$ & $\mathrm{TSP}^{\mathrm{e}}\left(\mathrm{m}^{2}\right)$ & Residue (wt\%) \\
\hline EP & $57 \pm 5$ & $1108 \pm 155$ & $96.2 \pm 1.3$ & $22.0 \pm 0.5$ & $31.9 \pm 3.1$ & $12.1 \pm 3$ \\
\hline EP/PM (2 wt\%) & $56 \pm 2$ & $970 \pm 100$ & $84.2 \pm 0.5$ & $21.8 \pm 0.3$ & $27.1 \pm 1.8$ & $14.5 \pm 3$ \\
\hline EP/PM (6 wt\%) & $54 \pm 3$ & $840 \pm 63$ & $78.5 \pm 6.4$ & $20.8 \pm 0.4$ & $24.6 \pm 0.5$ & $17.6 \pm 2$ \\
\hline EP/IC (2 wt\%) & $55 \pm 2$ & $905 \pm 65$ & $73.0 \pm 3.5$ & $21.0 \pm 0.3$ & $21.0 \pm 1.6$ & $17.1 \pm 2$ \\
\hline $\mathrm{EP} / \mathrm{IC}$ (6 wt\%) & $50 \pm 2$ & $541 \pm 50$ & $68.8 \pm 3.0$ & $19.8 \pm 0.3$ & $21.2 \pm 0.2$ & $19.2 \pm 3$ \\
\hline
\end{tabular}

TTI was time to ignition.

b pHRR was peak of heat release rate.

c THR was total heat release.

d EHC meant effective heat of combustion.

e TSP meant the total smoke production.

loading of IC or PM in EP, TTI of EP/IC showed at earlier time than that of $\mathrm{EP} / \mathrm{PM}$. A shift of TTI to the earlier time in EP/PM and EP/IC would be re lated to the thermal decomposition of PM and IC in EP.

HRR curves of EP, EP/PM ( 6 wt\%) and EP/IC ( 6 wt\%) were shown in Fig. 8(a). Compared with EP and EP/PM, a clear shoulder peak appeared on the main HRR peak of EP/IC ( 6 wt\%). The shoulder peak was at $64 \pm$ $5 \mathrm{~s}$ with a HRR value of $350 \pm 50 \mathrm{~kW} / \mathrm{m}^{2}$. Both pHRRs of EP/IC and EP/ PM were lower than that of EP. EP/IC ( 2 and 6 wt\%) showed pHRR values of $905 \pm 65$ and $541 \pm 50 \mathrm{~kW} / \mathrm{m}^{2}$, respectively. The pHRR of EP/IC (6 wt\%) showed $51 \%$ reduction compared with that of EP. pHRRs of $\mathrm{EP} / \mathrm{PM}$ ( 2 and 6 wt\%) were $970 \pm 100$ and $840 \pm 63 \mathrm{~kW} / \mathrm{m}^{2}$, respective ly, showing $12 \%$ and $24 \%$ reduction compared with that of EP. Clearly, the reductions of EP/IC were higher than that of EP/PM at the same load ing. THR of EP was reduced after the addition of PM or IC. THR of EP/PM (6 wt\%) decreased to $78.5 \pm 6.4 \mathrm{MJ} / \mathrm{m}^{2}$, while that of EP/IC ( $6 \mathrm{wt} \%$ ) de creased to $68.8 \pm 3.0 \mathrm{MJ} / \mathrm{m}^{2}$. EHC is the heat of combustion which would be expected in a fire where incomplete combustion takes place [54]. From Table 4, EHC values of EP/IC ( 2 and 6 wt\%) were $21.0 \pm 0.3$ and $19.8 \pm 0.3 \mathrm{MJ} / \mathrm{kg}$, respectively. Compared with EP and EP/PM, EP/ IC showed a relativity lower EHC value in this test. The reduction of EHC indicated that a possible flame retardant mechanism occurred in the gas phase. In Fig. 8(b), the mass loss rates of EP/PM (6 wt\%) and $\mathrm{EP} / \mathrm{IC}$ (6 wt\%) were lower compared with that of EP. The residue amounts of EP/IC (2 and $6 \mathrm{wt} \%$ ) were $17.1 \pm 2$ and $19.2 \pm 3 \mathrm{wt} \%$ which were higher than those of EP and EP/PM.

In addition, both the addition of IC and PM decreased TSP of EP, as shown in Fig. 8(d). TSP of EP/IC was lower than that of EP/PM. TSP of $\mathrm{EP} / \mathrm{PM}$ ( 2 and $6 \mathrm{wt} \%$ ) were $27.1 \pm 1.8 \mathrm{~m}^{2}$ and $24.6 \pm 0.5 \mathrm{~m}^{2}$, respective ly, which were lower than that of EP $\left(31.9 \pm 3.1 \mathrm{~m}^{2}\right)$. EP/IC $(2 \mathrm{wt} \%)$ showed TSP of $21.0 \pm 1.6 \mathrm{~m}^{2}$ which was $6.1 \mathrm{~m}^{2}$ lower than that of $\mathrm{EP} /$ $\mathrm{PM}$ (2 wt\%). In Fig. 9, $\mathrm{CO} / \mathrm{CO}_{2}$ release ratio of $\mathrm{EP} / \mathrm{IC}$ and $\mathrm{EP} / \mathrm{PM}$ were

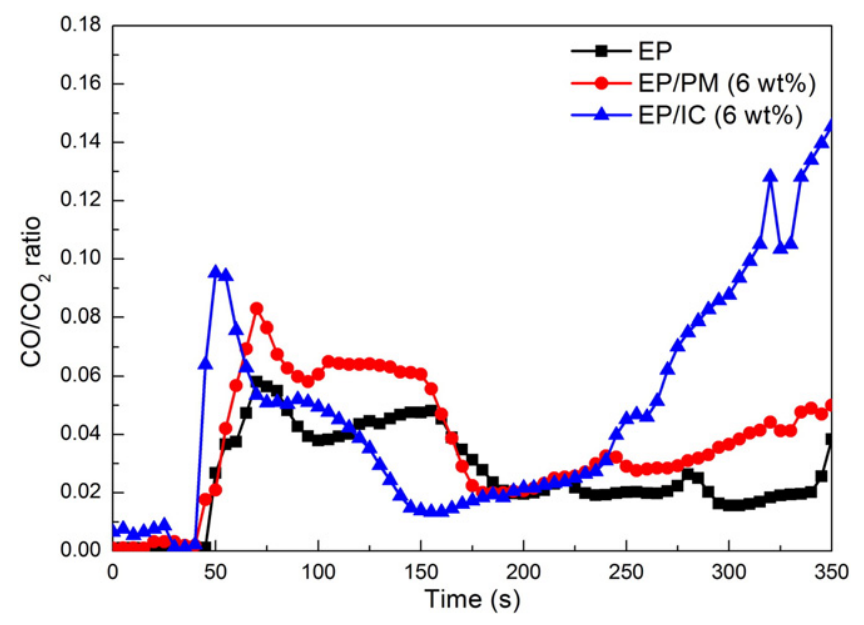

Fig. 9. The $\mathrm{CO} / \mathrm{CO}_{2}$ ratio curves of release rate of $\mathrm{EP}, \mathrm{EP} / \mathrm{PM}$ (6 wt $\%$ ) and $\mathrm{EP} / \mathrm{IC}(6 \mathrm{wt} \%)$. higher than that of EP, indicating incomplete combustion behavior oc curred during the combustion of EP/IC.

Overall, IC showed better effect on improving the flame retardancy of EP compared with PM. The LOI of EP was increased from $22.0 \%$ to $26.8 \%$ after the addition of IC. In cone calorimeter test, the heat release and smoke production of EP/IC were evidently suppressed compared with $\mathrm{EP}$ and $\mathrm{EP} / \mathrm{PM}$. However, the $\mathrm{CO} / \mathrm{CO}_{2}$ release ratio of $\mathrm{EP} / \mathrm{PM}$ and $\mathrm{EP} / \mathrm{IC}$ was higher than that of $\mathrm{EP}$, indicated a possible flame retardant mechanism occurred in the gas phase by adding PM and IC in EP.

\subsection{Flame retardant mechanism}

On the base of the results in Section 3.3, clearly the IC showed better flame retardancy to EP compared with PM; moreover, possible flame retardant mechanism was proposed as follows. On the one side, the res idue amount of EP/IC ( $6 \mathrm{wt} \%$ ) was $7.1 \%$ which was higher than that of EP in cone calorimeter test; the char residue of EP/IC was intumescence. This type of char residue was able to interrupt the gaseous (e.g. volatiles, air, etc.) and heat transfer during the combustion. These results indicat ed a flame retardant mechanism occurred in the condensed phase by incorporating the IC into EP. Possibly, when IC thermal decomposed, the host molecule $(\beta C D)$ acted as char precursor due to the polyol structure; the guest structure (P MA) acted as acid source which were able to accelerate the char formation. On the other side, the fact that is the decreased EHC values of EP/IC (6 wt\%) and its increased ratio of $\mathrm{CO} / \mathrm{CO}_{2}$ compared with those EP indicated IC acted in the gas phase to reduce the flammability of $\mathrm{EP}$. Based upon the conclusions in the previ ous report $[44,45]$, phenylphosphonate based flame retardant showed effectively flame inhibition during the combustion of EP. However, such mechanism might not be the dominant flame retardant mecha nism in EP/IC due to the fact that the weight percent of P MA in EP/IC (6 wt\%) was only 0.69 wt\%.

\section{Conclusions}

In this work, IC was synthesized via the inclusion behavior between $\beta$ CD and P MA and characterized by ${ }^{1} \mathrm{H}$ NMR, FTIR, XRD, DSC, and SEM EDS methods. The inclusion ratio of $\beta C D$ and $P$ MA was 2:1 and possi ble inclusion structures were proposed according to the results of ${ }^{1} \mathrm{H}$ NMR spectra. The results of TGA under $\mathrm{N}_{2}$ showed that the charring abil ity of IC was higher than those of PM. The char residue of PM was $16.8 \%$, while that of IC was $25.9 \%$ at $600{ }^{\circ} \mathrm{C}$. The initial thermal decomposing temperature of IC was increased remarkably above $250{ }^{\circ} \mathrm{C}$ which was improved compared with PM.

The flame retardancy of EP/IC was lower compared with that of EP and EP/PM. LOI of EP/PM (2 wt\%) was $24.5 \%$, whereas that of EP/IC (2 wt\%) was $26.5 \%$. In cone calorimeter test, pHRR of EP/IC (6 wt\%) were $541 \mathrm{~kW} / \mathrm{m}^{2}$ which was lower by $36 \%$ compared with $\mathrm{EP} /$ $\mathrm{PM}(6 \mathrm{wt} \%)$. In addition, TSP of EP/IC was $6.1 \mathrm{~m}^{2}$ lower than that of EP/ $\mathrm{PM}$ at $2 \mathrm{wt} \%$ loading. The reduction of EHC values and increased $\mathrm{CO} /$ $\mathrm{CO}_{2}$ release rate ratio showed that IC acted in the gas phase during the 
burning of EP/IC. Flame retardant mechanism of IC in EP was proposed in both condensed and gas phases.

\section{Acknowledgements}

One of our authors (Ms. Xiaomin Zhao) would thank the financial support from China Scholarship Council (201206230082). In addition, this work is supported by Ramón y Cajal grant (RYC 2012 10737) and COST Action CM1302 European Network on Smart Inorganic Polymers (SIPs).

\section{References}

[1] C. May, Epoxy Resins: Chemistry and Technology, CRC press, 1987.

[2] X. Zhang, Q. He, H. Gu, H.A. Colorado, S. Wei, Z. Guo, Flame-retardant electrical conductive nanopolymers based on bisphenol $\mathrm{F}$ epoxy resin reinforced with nanopolyanilines, ACS Appl. Mater. Interfaces 5 (2013) 898-910.

[3] M. Rakotomalala, S. Wagner, M. Döring, Recent developments in halogen free flame retardants for epoxy resins for electrical and electronic applications, Materials 3 (2010) 4300-4327.

[4] J. Alongi, F. Bosco, F. Carosio, A. Di Blasio, G. Malucelli, A new era for flame retardant materials? Mater. Today 17 (2014) 152-153.

[5] X.-W. Cheng, J.-P. Guan, R.-C. Tang, K.-Q. Liu, Phytic acid as a bio-based phosphorus flame retardant for poly (lactic acid) nonwoven fabric, J. Clean. Prod. 124 (2016) 114-119.

[6] Y. Liu, C.-J. Zhang, J.-C. Zhao, Y. Guo, P. Zhu, D.-Y. Wang, Bio-based barium alginate film: preparation, flame retardancy and thermal degradation behavior, Carbohydr. Polym. 139 (2016) 106-114

[7] N.-J. Kang, D.-Y. Wang, A green functional nanohybrid: preparation, characterization and properties of a $\beta$-cyclodextrin based functional layered double hydroxide, J. Mater. Chem. A 1 (2013) 11376-11383.

[8] M. Shabanian, N. Kang, J. Liu, U. Wagenknecht, G. Heinrich, D.-Y. Wang, Bio-based semi-aromatic polyamide/functional clay nanocomposites: preparation and properties, RSC Adv. 4 (2014) 23420-23427.

[9] E.N. Kalali, X. Wang, D.-Y. Wang, Multifunctional intercalation in layered double hydroxide: toward multifunctional nanohybrids for epoxy resin, J. Mater. Chem. A 4 (2016) 2147-2157.

[10] F. Carosio, A. Di Blasio, J. Alongi, G. Malucelli, Polymer 54 (2013) 5148-5153.

[11] F. Bosco, R.A. Carletto, J. Alongi, L. Marmo, A. Di Blasio, G. Malucelli, Thermal stability and flame resistance of cotton fabrics treated with whey proteins, Carbohydr. Polym. 94 (2013) 372-377.

[12] G. Crini, Review: a history of cyclodextrins, Chem. Rev. 114 (2014) 10940-10975.

[13] S. Nikolai, P. Huebbe, C.C. Metges, A. Schloesser, J. Dose, N.K. Ikuta, S. Matsugo, G. Rimbach, R- $\alpha$ lipoic acid $\gamma$-cyclodextrin complex increases energy expenditure: a 4-month feeding study in mice, Nutrition 30 (2014) 228-233.

[14] B. Kaboudin, R. Mostafalu, T. Yokomatsu, $\mathrm{Fe}_{3} \mathrm{O}_{4}$ nanoparticle-supported Cu (II)- $\beta$-cyclodextrin complex as a magnetically recoverable and reusable catalyst for the synthesis of symmetrical biaryls and 1, 2, 3-triazoles from aryl boronic acids, Green Chem. 15 (2013) 2266-2274.

[15] A.-J. Tong, A. Yamauchi, T. Hayashita, Z.-Y. Zhang, B.D. Smith, N. Teramae, Boronic acid fluorophore/ $\beta$-cyclodextrin complex sensors for selective sugar recognition in water, Anal. Chem. 73 (2001) 1530-1536

[16] F. Maestrelli, N. Zerrouk, M. Cirri, N. Mennini, P. Mura, Microspheres for colonic delivery of ketoprofen-hydroxypropyl- $\beta$-cyclodextrin complex, Eur. J. Pharm. Sci. 34 (2008) 1-11.

[17] J. Zhang, P.X. Ma, Cyclodextrin-based supramolecular systems for drug delivery: recent progress and future perspective, Adv. Drug Deliv. Rev. 65 (2013) 1215-1233.

[18] S.W. Jun, M.-S. Kim, J.-S. Kim, H.J. Park, S. Lee, J.-S. Woo, S.-J. Hwang, Preparation and characterization of simvastatin/hydroxypropyl-3-cyclodextrin inclusion complex using supercritical antisolvent (SAS) process, Eur. J. Pharm. Biopharm. 66 (2007) 413-421.

[19] J.X. Feng, S.P. Su, J. Zhu, An intumescent flame retardant system using $\beta$-cyclodextrin as a carbon source in polylactic acid (PLA), Polym. Adv. Technol. 22 (2011) $1115-1122$

[20] N. Zhang, J. Shen, M.A. Pasquinelli, D. Hinks, A.E. Tonelli, Formation and characterization of an inclusion complex of triphenyl phosphate and $\beta$-cyclodextrin and its use as a flame retardant for polyethylene terephthalate, Polym. Degrad. Stab. 120 (2015) 244-250.

[21] J. Alongi, M. Pošković, A. Frache, F. Trotta, Novel flame retardants containing cyclodextrinnanosponges and phosphorus compounds to enhance EVA combustion properties, Polym. Degrad. Stab. 95 (2010) 2093-2100.

[22] K.A. Salmeia, S. Gaan, An overview of some recent advances in DOPO-derivatives: chemistry and flame retardant applications, Polym. Degrad. Stab. 113 (2015) 119-134.

[23] M. Ciesielski, B. Burk, C. Heinzmann, M. Döring, 2 - Fire-Retardant High-performance Epoxy-based Materials A2 - Wang, De-Yi, Novel Fire Retardant Polymers and Composite Materials, Wood head Publishing, 2017 3-51.

[24] M. Ciesielski, A. Schäfer, M. Döring, Novel efficient DOPO-based flame-retardants for PWB relevant epoxy resins with high glass transition temperatures, Polym. Adv. Technol. 19 (2008) 507-515.
[25] M. Rakotomalala, S. Wagner, M. Döring, Recent developments in halogen free flame retardants for epoxy resins for electrical and electronic applications, Materials 3 (2010) 4300-4327.

[26] C. Klinkowski, S. Wagner, M. Ciesielski, M. Döring, Bridged phosphorylated diamines: synthesis, thermal stability and flame retarding properties in epoxy resins, Polym. Degrad. Stab. 106 (2014) 122-128.

[27] B. Schartel, B. Perret, B. Dittrich, M. Ciesielski, J. Krämer, P. Müller, V. Altstädt, L. Zang, M. Döring, Flame retardancy of polymers: the role of specific reactions in the condensed phase, Macromol. Mater. Eng. 301 (2016) 9-35.

[28] B. Perret, B. Schartel, K. Stöß, M. Ciesielski, J. Diederichs, M. Döring, J. Krämer, V. Altstädt, Novel DOPO-based flame retardants in high-performance carbon fibre epoxy composites for aviation, Eur. Polym. J. 47 (2011) 1081-1089.

[29] B. Schartel, Phosphorus-based flame retardancy mechanisms-old hat or a starting point for future development? Materials 3 (2010) 4710-4745.

[30] B. Perret, B. Schartel, K. Stöß, M. Ciesielski, J. Diederichs, M. Döring, J. Krämer, V. Altstädt, Novel DOPO-based flame retardants in high-performance carbon fibre epoxy composites for aviation, Eur. Polym. J. 47 (2011) 1081-1089.

[31] W. Zhang, X. Li, R. Yang, Study on flame retardancy of TGDDM epoxy resins loaded with DOPO-POSS compound and OPS/DOPO mixture, Polym. Degrad. Stab. 99 (2014) 118-126.

[32] W. Zhang, A. Fina, F. Cuttica, G. Camino, R. Yang, Blowing-out effect in flame retarding epoxy resins: insight by temperature measurements during forced combustion, Polym. Degrad. Stab. 131 (2016) 82-90.

[33] W. Zhang, X. Li, H. Fan, R. Yang, Study on mechanism of phosphorus-silicon synergistic flame retardancy on epoxy resins, Polym. Degrad. Stab. 97 (2012) 2241-2248.

[34] X. Wang, Y. Hu, L. Song, W. Xing, H. Lu, P. Lv, G. Jie, Flame retardancy and thermal degradation mechanism of epoxy resin composites based on a DOPO substituted organophosphorus oligomer, Polymer 51 (2010) 2435-2445.

[35] X. Oian, L. Song, Y. Hu, R.K. Yuen, L. Chen, Y. Guo, N. Hong, S. Jiang, Combustion and thermal degradation mechanism of a novel intumescent flame retardant for epoxy acrylate containing phosphorus and nitrogen, Ind. Eng. Chem. Res. 50 (2011) 1881-1892.

[36] K. Wu, L. Song, Y. Hu, H. Lu, B.K. Kandola, E. Kandare, Synthesis and characterization of a functional polyhedral oligomeric silsesquioxane and its flame retardancy in epoxy resin, Prog. Org. Coat. 65 (2009) 490-497.

[37] X. Wang, W. Xing, P. Zhang, L. Song, H. Yang, Y. Hu, Covalent functionalization of graphene with organosilane and its use as a reinforcement in epoxy composites, Compos. Sci. Technol. 72 (2012) 737-743.

[38] A. Toldy, Á. Szlancsik, B. Szolnoki, Reactive flame retardancy of cyanate ester/epoxy resin blends and their carbon fibre reinforced composites, Polym. Degrad. Stab. 128 (2016) 29-38.

[39] A. Toldy, B. Szolnoki, G. Marosi, Flame retardancy of fibre-reinforced epoxy resin composites for aerospace applications, Polym. Degrad. Stab. 96 (2011) 371-376.

[40] A. Toldy, B. Szolnoki, I. Csontos, G. Marosi, Green synthesis and characterization of phosphorus flame retardant crosslinking agents for epoxy resins, J. Appl. Polym. Sci. (2014) 5v.

[41] P.M. Hergenrother, C.M. Thompson, J.G. Smith, J.W. Connell, J.A. Hinkley, R.E. Lyon, R. Moulton, Flame retardant aircraft epoxy resins containing phosphorus, Polymer 46 (2005) 5012-5024.

[42] D. Sun, Y. Yao, Synthesis of three novel phosphorus-containing flame retardants and their application in epoxy resins, Polym. Degrad. Stab. 96 (2011) 1720-1724.

[43] C. Gérard, G. Fontaine, S. Bourbigot, Synergistic and antagonistic effects in flame retardancy of an intumescent epoxy resin, Polym. Adv. Technol. 22 (2011) 1085-1090.

[44] X. Zhao, H. Vignesh, J. Llorca, D.-Y. Wang, Impact of halogen-free flame retardant with varied phosphorus's chemical surrounding on the properties of diglycidyl ether of bisphenol-A type epoxy resin: synthesis, fire behaviour, flame-retardant mechanism and mechanical properties, RSC Adv. 6 (2016) 59226-59236.

[45] X. Zhao, L. Yang, M.H. Francisco, D.-Y. Wang, Impact of phenylphosphonate based flame retardant on epoxy/glass fiber reinforced composites (GRE): flammability, thermal stability and mechanical properties, Compos. Part B (2016)http://dx.doi. org/10.1016/j.compositesb.2016.10.090.

[46] B. Liu, X. Zhu, J. Zeng, J. Zhao, Preparation and physicochemical characterization of the supramolecular inclusion complex of naringindihydrochalcone and hydroxypropyl- $\beta$-cyclodextrin, Food Res. Int. 54 (2013) 691-696.

[47] Y.A. Gao, Z.H. Li, J.M. Du, B.X. Han, G.Z. Li, W.G. Hou, D. Shen, L.Q. Zheng, G.Y. Zhang, Preparation and characterization of inclusion complexes of $\beta$-cyclodextrin with ionic liquid, Chem. Eur. J. 11 (2005) 5875-5880.

[48] H.-J. Schneider, F. Hacket, V. Rüdiger, H. Ikeda, NMR studies of cyclodextrins and cyclodextrin complexes, Chem. Rev. 98 (1998) 1755-1786.

[49] J. Wang, Y. Cao, B. Sun, C. Wang, Characterisation of inclusion complex of transferulic acid and hydroxypropyl- $\beta$-cyclodextrin, Food Chem. 124 (2011) 1069-1075.

[50] L. Liu, S. Zhu, A study on the supramolecular structure of inclusion complex of $\beta$-cyclodextrin with prazosin hydrochloride, Carbohydr. Polym. 68 (2007) 472-476.

[51] A. Mele, F. Castiglione, L. Malpezzi, F. Ganazzoli, G. Raffaini, F. Trotta, B. Rossi, A Fontana, G. Giunchi, HR MAS NMR, powder XRD and Raman spectroscopy study of inclusion phenomena in $\mathrm{BCD}$ nanosponges, J. Incl. Phenom. Macrocycl. Chem. 69 (2011) 403-409.

[52] B.G. Kutchko, A.G. Kim, Fly ash characterization by SEM-EDS, Fuel 85 (2006) 2537-2544.

[53] S. Bourbigot, E. Devaux, X. Flambard, Flammability of polyamide-6/clay hybrid nanocomposite textiles, Polym. Degrad. Stab. 75 (2002) 397-402.

[54] L. Shi, M.Y.L. Chew, Fire behaviors of polymers under autoignition conditions in a cone calorimeter, Fire Saf. J. 61 (2013) 243-253. 